\title{
When science informed policy
}

\author{
William H. Schlesinger
}

Published online: 10 March 2017

(C) Springer International Publishing Switzerland 2017

At any moment, science gives us its best explanation of reality. It proceeds by rigorous tests of hypotheses through observation and experimentation. For centuries, we thought the Earth was the center of the universe, until Galileo used the scientific method to prove otherwise. Universities are full of those who hope to disprove existing postulates; certain fame awaits a scientist who can overturn dogma. In this way, good science replaces bad science. The progressive refinement of science has brought us modern health care, abundant food, and many of the conveniences of daily life.

We all trust science when we read the daily weather forecast and decide what to wear to work. Later in the day, we may change our understanding of reality, but as we leave for work, we act with the best knowledge we have at the moment. That knowledge is informed by the science of meteorology and its models of how the weather system works. Like all science, meteorology undergoes constant scrutiny and refinement. Its predictions will improve with time, but for the moment, only a rain dance offers an alternative.

More than a century ago, the Swedish chemist Svante Arrhenius suggested that the radiative properties of carbon dioxide in the atmosphere would warm the Earth. His prediction has withstood experimental

W. H. Schlesinger $(\square)$

Cary Institute of Ecosystem Studies, Millbrook, NY, USA

e-mail: schlesingerw@caryinstitute.org tests. We are now living in that reality, and the scientific community has achieved unprecedented consensus on the fate of a planet with rising $\mathrm{CO}_{2}$ in its atmosphere.

Certainly, if new science provided better explanations for the factors that control the temperature of our planet, the scientific world would embrace them. But countless scholars who have tried to leave their mark on the field of atmospheric physics have failed to provide alternative explanations of substance.

I marvel, then, that those who simply wish the world worked otherwise can prevail in the publicpolicy world. The contrarians of global warming do not muster what is known from science to support their views; rather, they trust their beliefs to be true even in the face of science. For scientists to sit quietly while the misinformed determine government policy on major environmental issues is an unacceptable return on the public investment in our work.

Nowhere is this more apparent than in the current debate about climate change, where a small ideological minority persists in disrupting the creation of effective policy-not basing their criticism on science but using an active program of "alternative facts" to confuse the issue. Many of these ideologues have a deep stake in the status quo. Unfortunately, speaking against the "alternative facts" of the contrarians has now reduced scientists to the status of a specialinterest group. 
We all are vulnerable to global warming, whether from an increased exposure to tropical disease, rising sea levels that may flood coastal cities, or catastrophic crop failures in the Great Plains. Firm government action to prevent climate change is as crucial to our future as the prevention of terrorism and the suppression of nuclear weapons. Unfortunately, the longer we wait to limit the emissions of carbon dioxide into the atmosphere, the less likely it is that we will avoid the negative impacts of global warming. Management of a planet does not turn on a dime.

Science must not be politicized but scientists are not advocates when their expertise informs the political process. While genomics, nanotechnology, and computer science can often promise a better world, environmental science frequently warns us of the dangers that lie ahead. A better world will depend on a functioning and healthy natural world. For environmental scientists, success is often manifest by the forest that wasn't cut. So too is it for air and water that are not polluted, for species that are not endangered, and for a stabilized climate within the boundaries of our evolutionary past.

Whatever policies we adopt to mitigate climate change must be simple, fair, and effective. Increasingly scientists, economists, and conservative policy makers are recognizing that a tax on carbon from fossil fuels has these characteristics. Scientists will have a role in showing what carbon credits should count and what putative credits are bogus.

As the cause for the ongoing changes in our climate are debated over the next few months, tested scientific facts, not "alternative facts," should be the basis of every decision and action. And we must act soon.

William H. Schlesinger is James B. Duke Professor of Biogeochemistry, Emeritus at Duke University, and past president of the Cary Institute of Ecosystem Studies, Millbrook, NY. 